http://jmscr.igmpublication.org/home/ ISSN (e)-2347-176x ISSN (p) 2455-0450 crossref DOI: https://dx.doi.org/10.18535/jmscr/v8i1.14

\title{
Alcohol consumption, tobacco use and lipid profile in Alcoholics attending a tertiary care hospital
}

\author{
IGM Publication \\ Journal Of Medical Science And Clinical Research \\ An Official Publication of IGM Publication
}

Authors

\author{
Dr S. Vignesh ${ }^{1 *}$, Dr K. Nagarajan ${ }^{2}$, Dr P. Anand ${ }^{3}$ \\ ${ }^{1}$ Postgraduate, Department of General Medicine \\ ${ }^{2}$ Professor, Department of General Medicine \\ ${ }^{3}$ Assistant Professor, Department of General Medicine \\ *Corresponding Author \\ Dr S. Vignesh \\ Sri Manakula Vinayagar Medical College and Hospital, Puducherry-605107, India
}

\begin{abstract}
Introduction: Alcohol abuse is one of the most common form of addiction prevalent all over the world. It affects all the major systems of the body. Consumption of alcohol in large amounts for a long duration produces toxic effects on liver, thus impairing the lipid metabolism, and hence alteration of serum lipid profile.
\end{abstract}

Objective: To study the association between amounts of alcohol consumed, tobacco usage and serum fasting lipid profile among alcoholics.

Methodology: We conducted a cross sectional study among alcoholics and smokers. Fasting lipid profile and other baseline investigations were done to study the association between alcohol consumption, tobacco usage and serum fasting lipid profile.

Results: In this study, a total of 40 males were studied, out of which 40 were alcoholics (duration of $>5$ years with $>60 \mathrm{ml} /$ day of intake of alcohol) and smokers. The complete serum lipid profile were estimated. The Mean Triglycerides in alcoholics were found to be 182. The Mean Total Cholesterol and LDL-C were found to be 197.47 and 144 . VLDL-C and HDL-C mean were 50.15 and 33.80 respectively. We found that the levels of serum TG, T Cholesterol, $L D L-C$ and $V L D L-C$ were raised in the alcoholics. But the HDL-C (good cholesterol) was found to be decreased in alcoholics. $P$ value was found to be $<0.05$, which is highly significant.

Conclusion: Alcohol use was strongly associated with an deranged lipid profile predisposing to increased risk for cardiovascular diseases. Health promotion programmes should therefore be instituted at a much earlier stage in life to prevent development of diseases.

Keywords: total cholesterol, alcoholics, fasting lipid profile, cardiovascular diseases.

\section{Introduction}

Alcohol dependence syndrome is a previous psychiatric diagnosis in which individuals is physically or psychologically dependent on alcohol. Alcohol abuse is one of the major forms of addiction seen in developed as well as developing countries. ${ }^{1}$ India too carries a significant burden of this. According to WHO reports of 2014, alcoholism alone causes 5.9\% deaths every year and the burden of the disease 
accounting to $5.1 \%$. Drinking alcohol is associated with the risk of developing of health problems such as alcohol dependence, liver cirrhosis, cardiovascular diseases and cancers. ${ }^{4}$ The over use of alcohol can also have serious social and economic consequences for the individual, family as well as for the society at a large. The use of alcoholic beverages has been an integral part of many cultures from thousands of years. ${ }^{2}$ Alcohol consumption has been identified as a component cause of more than 200 diseases, injuries and other health problems. Volume of alcohol consumed the pattern of drinking and quality of alcohol intake has a great impact on the health of an individual. ${ }^{5}$ There are three main direct mechanisms of harm caused by alcohol consumption in an individual. These are (i).Toxic effects on organs and tissues.(ii).Intoxication, leading to impairment of physical coordination, consciousness, cognition, perception, affect or behaviour. (iii). Dependence, whereby the drinker's self-control over his or her drinking behaviour is impaired. Liver plays an important role in lipid metabolism for two main reasons namely (a) The bile salts are formed in the liver which are necessary for emulsification and absorption of fats are excreted by liver (b) It is concerned with the metabolism of cholesterol. ${ }^{3}$ Marked alterations in lipid metabolism have been reported on chronic ethanol feeding. The accumulation of fat in the liver on chronic alcohol intake acts as a stimulus for the secretion of lipoproteins into the blood stream and the development of hyper lipidemia. ${ }^{2}$ Decreased fatty acid oxidation in the liver or increased fatty acid synthesis or both would increase the availability of substrate for lipoprotein synthesis. Moreover, lipoproteins are chemically modified by oxidation. ${ }^{4}$ These oxidized or modified lipoproteins do not react with LDL receptors leading to esterification of cholesterol and conversion of macrophages to foam cells, thereby contributing to the hyper lipidemia observed on alcohol consumption. ${ }^{6}$ In alcoholics, the metabolism of alcohol produces increased amounts of reduced hepatic nicotinamide adenine nucleotide $(\mathrm{NADH}+)$. Increased $\mathrm{NADH} 2 / \mathrm{NAD}$ ratio inhibits the oxidation of fatty acids. ${ }^{3}$ Fatty acids reaching the liver either from dietary sources or by mobilization from adipose tissue are therefore re-esterified with glycerol to form triglycerides. In initial stages of alcoholism, these are packaged with apolipoproteins and exported as very-low-density lipoproteins (VLDL). ${ }^{6}$ Increased concentrations of VLDL and hence of serum triglycerides are often present in early stages of alcoholic liver disease. As the liver disease progresses, there is failure to produce apolipoproteins and export the fat as VLDL, thus accumulation of TG ensues. ${ }^{1}$ Chronic alcohol misuse and abuse has serious effects on physical and mental health. Chronic excess alcohol intake, or alcohol dependence, leads to neuropsychiatric or neurological impairment, cardiovascular disease, liver disease, and malignant neoplasms. The psychiatric disorders which are associated with alcoholism include major depression, dysthymia, mania, hypomania, panic disorder, phobias, generalized anxiety disorder, personality disorders, schizophrenia, suicide, neurologic deficits (e.g. impairments of working memory, emotions, executive functions, visuospatial abilities and gait and balance) and brain damage. Alcohol dependence is associated with hypertension, coronary heart disease, and ischemic stroke, cancer of the respiratory system, and also cancers of the digestive system, liver, breast and ovaries. Heavy drinking is associated with liver disease, such as cirrhosis. The amount of alcohol consumption which leads to coronary mortality can be decreased, so that the number of deaths due to alcoholism can be reduced. ${ }^{2}$

Though many studies were done in finding the association between alcohol usage and its effect on lipid derangement, context specific studies were rare to the bet of our knowledge and studies exploring the association between the dose of alcohol consumed and its effect on lipid abnormality were rare. Hence the present study is designed. 


\section{Materials and Methods}

Study area and design: This study was done at Sri Manakula Vinayagar Medical College and Hospital from March to August 2018 for a period of six months. Sri manakula vinayagar medical college is a tertiary care hospital located at madagadipet, Puducherry. The study design employed was a cross sectional study.

Study setting: The study conducted in the Department of General Medicine of Sri Manakula Vinayagar Medical College and Hospital, Puducherry. The hospital provides service to patients predominantly residing in Puducherry and neighboring district of Tamil Nadu. On an average 150 out patients and 15 in-patients get medical care from the Medicine Department.

Study Design: Hospital based cross sectional study

Duration of Study: Six Months.

Study Population: Study population will be alcoholics and smokers.

\section{Inclusion Criteria}

1) Age groups 30-65 years of age

2) Both gender

Exclusion Criteria: Patients with the following diseases will be excluded

1) Known cases of liver disorders

2) Cardiovascular diseases

3) Renal disorders

4) Diabetes mellitus

Sample Size: The calculated sample size using the software Open Epi version 3.0, taking into consideration mean (SD) triglyceride value among alcoholics consume high levels of alcohol and who consume low level as 116(1.6) $\mathrm{mg} / \mathrm{dl}$ and 120 (2.9) $\mathrm{mg} / \mathrm{dl}$ from previous study1, with $95 \%$ confidence interval, $80 \%$ power and $10 \%$ nonresponse rate was very less (20). It was decided to study 40 patients.

Sampling Technique: All eligible patients attending the Medicine OPD and admitted in Medicine and Psychiatry ward during the study period will be included till the calculated sample size is achieved.

\section{Study Procedure}

After obtaining clearance from IEC the study will be carried out. Written and informed consent will be obtained before collecting information from patients. If he is found to have the diagnosis then he will be assessed for the eligibility to enroll in the study. If eligible the details of alcohol and tobacco usage will be collected with the help of questionnaire

\section{Study variables and method of data collection}

1. Socio demographic details (age, gender, socio economic status) using prestructured questionnaire

2. Clinical profile (symptoms, duration, complications etc)

3. Fasting/Postprandial blood sugar are calculated by Glucose oxidase and glucose peroxidase method. (cut off values being FBS-106 He will be instructed to check his fasting lipid profile the next day and other relevant investigations. $\mathrm{mg} / \mathrm{dl}$, PPBS$140 \mathrm{mg} / \mathrm{dl}$ )

4. $\mathrm{HbA} 1 \mathrm{c}$

5. Electrocardiogram

6. Two dimensional echocardiography(with significant changes)

7. Lipid profile

a) Total Cholesterol Estimation : CHOD / POD Method

b) HDL cholesterol estimation : Direct enzymatic method

c) Triglyceride: Direct enzymatic method.

d) Low density lipoprotein cholesterol (LDL-C)

e) Very low density lipoprotein cholesterol (VLDL-C)

8. Liver Function Test

9. Renal Function Test

10. Alcohol consumption per day in $\mathrm{g} / \mathrm{dl}$ of various alcoholic beverages.

\section{Statistcal Analysis Plan}

Data obtained from the subjects will be entered using Epi Info software version 4.2 and will be analyzed with the use of computer software SPSS 
version 24. Description of categorical variables will be done in proportions and frequency and that of continuous variables in mean and standard deviation. Association between the levels of alcohol and lipid derangement will be done using students $\mathrm{t}$ test. All tests will be two tailed and $\mathrm{p}$ value $<0.05$ will be considered statistically significant.

\section{Results}

Table 1: Distribution of the Participants in Terms of Age (Years) $(n=40)$

\begin{tabular}{|c|c|}
\hline \multicolumn{2}{|c|}{ Age (Years) } \\
\hline Mean (SD) & $53.77(5.63)$ \\
\hline Median (IQR) & $55(8.25)$ \\
\hline Range & $42-64$ \\
\hline
\end{tabular}

The variable Age (Years) was normally distributed (Shapiro-Wilk Test: $p=0.509$ ).

The mean (SD) of Age (Years) was 53.77 (5.63).

The median (IQR) of Age (Years) was 55.00 (8.25). The Age (Years) ranged from 42 - 64.

\section{Distribution of the Participants in Terms of Gender $(\mathbf{n}=\mathbf{4 0})$ \\ $100.0 \%$ of the participants had Gender: Male.}

Table 2: Distribution of the Participants in terms of Duration of Alcohol Use (Years)

$(\mathrm{n}=40)$

\begin{tabular}{|c|c|}
\hline \multicolumn{2}{|c|}{ Duration of Alcohol Use (Years) } \\
\hline Mean (SD) & $15.05(5.54)$ \\
\hline Median (IQR) & $14(9.25)$ \\
\hline Range & $7-30$ \\
\hline
\end{tabular}

The variable Duration of Alcohol Use (Years) was not normally distributed (Shapiro-Wilk Test: $\mathrm{p}=$ 0.012).

The mean (SD) of Duration of Alcohol Use (Years) was 15.05 (5.54). The median (IQR) of Duration of Alcohol Use (Years) was 14.00 (9.25). The Duration of Alcohol Use (Years) ranged from 7 - 30 .
Table 3: Distribution of the Participants in Terms of Duration of Smoking (Years) $(n=40)$

\begin{tabular}{|c|c|}
\hline \multicolumn{2}{|c|}{ Duration of Smoking (Years) } \\
\hline Mean (SD) & $7.53(8.33)$ \\
\hline Median (IQR) & $5(15)$ \\
\hline Range & $0-25$ \\
\hline
\end{tabular}

The variable Duration of Smoking (Years) was not normally distributed (Shapiro-Wilk Test: $\mathrm{p}=$ $<0.001)$.

The mean (SD) of Duration of Smoking (Years) was 7.53 (8.33). The median (IQR) of Duration of Smoking (Years) was 5.00 (15.00). The Duration of Smoking (Years) ranged from 0 - 25.

Table 4: Distribution of the Participants in Terms of Weekly Alcohol Consumption (Grams) $(\mathrm{n}=40)$

\begin{tabular}{|c|c|}
\hline \multicolumn{2}{|c|}{ Weekly Alcohol Consumption (Grams) } \\
\hline Mean (SD) & $154.62(55.90)$ \\
\hline Median (IQR) & $145(92.5)$ \\
\hline Range & $80-280$ \\
\hline
\end{tabular}

The variable Weekly Alcohol Consumption (Grams) was not normally distributed (ShapiroWilk Test: $p=0.005)$.

The mean (SD) of Weekly Alcohol Consumption (Grams) was 154.62 (55.90). The median (IQR) of Weekly Alcohol Consumption (Grams) was 145.00 (92.50). The Weekly Alcohol Consumption (Grams) ranged from 80 - 280.

Table 5: Distribution of the Participants in Terms of Number of Cigarettes Smoked Per Day $(n=40)$

\begin{tabular}{|c|c|}
\hline \multicolumn{2}{|c|}{ Number of Cigarettes Smoked Per Day } \\
\hline Mean (SD) & $2.23(2.38)$ \\
\hline Median (IQR) & $1.5(4)$ \\
\hline Range & $0-7$ \\
\hline
\end{tabular}

The variable Number of Cigarettes Smoked Per Day was not normally distributed (Shapiro-Wilk Test: $\mathrm{p}=<0.001)$.

The mean (SD) of Number of Cigarettes Smoked Per Day was 2.23 (2.38). The median (IQR) of Number of Cigarettes Smoked Per Day was 1.50 (4.00). The Number of Cigarettes Smoked Per Day ranged from $0-7$. 
Table 1: Summary of Parameters

\begin{tabular}{|l|c|}
\hline Parameters & Mean \pm SD/N $(\%)$ \\
\hline Age (Years) & $53.77 \pm 5.63$ \\
\hline Gender (Male) & $40(100.0 \%)$ \\
\hline Duration of Alcohol Use (Years) & $15.05 \pm 5.54$ \\
\hline Duration of Smoking (Years) & $7.53 \pm 8.33$ \\
\hline Weekly Alcohol Consumption (Grams) & $154.62 \pm 55.90$ \\
\hline Number of Cigarettes Smoked Per Day & $2.23 \pm 2.38$ \\
\hline Total Cholesterol (mg/dl) & $197.47 \pm 51.65$ \\
\hline Total Cholesterol & \\
\hline$<220 \mathrm{mg} / \mathrm{dl}$ & $23(57.5 \%)$ \\
\hline$>220 \mathrm{mg} / \mathrm{dl}$ & $17(42.5 \%)$ \\
\hline Triglycerides (mg/dl) & $182.00 \pm 45.10$ \\
\hline Triglycerides & \\
\hline$<160 \mathrm{mg} / \mathrm{dl}$ & $16(40.0 \%)$ \\
\hline$>160 \mathrm{mg} / \mathrm{dl}$ & $24(60.0 \%)$ \\
\hline HDL $(\mathbf{m g} / \mathbf{d l})$ & $33.80 \pm 6.89$ \\
\hline HDL & \\
\hline$<35 \mathrm{mg} / \mathrm{dl}$ & $22(55.0 \%)$ \\
\hline$>35 \mathrm{mg} / \mathrm{dl}$ & $18(45.0 \%)$ \\
\hline LDL (mg/dl) & $144.00 \pm 26.01$ \\
\hline LDL & \\
\hline$<165 \mathrm{mg} / \mathrm{dl}$ & $33(82.5 \%)$ \\
\hline$>165 \mathrm{mg} / \mathrm{dl}$ & $7(17.5 \%)$ \\
\hline VLDL (mg/dl) & $50.15 \pm 12.27$ \\
\hline VLDL & \\
\hline$<35 \mathrm{mg} / \mathrm{dl}$ & $5(12.5 \%)$ \\
\hline$>35 \mathrm{mg} / \mathrm{dl}$ & $35(87.5 \%)$ \\
\hline
\end{tabular}

Table 2: Association between Duration of Alcohol Use (Years) and Parameters

\begin{tabular}{|l|c|c|}
\hline Parameters & Duration of Alcohol Use (Years) & p value \\
\hline Age (Years) & rho $=0.17$ & $0.306^{1}$ \\
\hline Total Cholesterol (mg/dl) & rho $=0.17$ & $0.293^{1}$ \\
\hline Total Cholesterol & & $0.322^{2}$ \\
\hline$<220 \mathrm{mg} / \mathrm{dl}$ & $14.52 \pm 5.88$ & \\
\hline$>220 \mathrm{mg} / \mathrm{dl}$ & $15.76 \pm 5.12$ & $0.242^{1}$ \\
\hline Triglycerides $(\mathbf{m g} / \mathbf{d l})$ & rho $=0.19$ & $0.216^{2}$ \\
\hline Triglycerides & & \\
\hline$<160 \mathrm{mg} / \mathrm{dl}$ & $14.00 \pm 5.65$ & \\
\hline$>160 \mathrm{mg} / \mathrm{dl}$ & $15.75 \pm 5.47$ & $0.763^{1}$ \\
\hline HDL $(\mathbf{m g} / \mathbf{d l})$ & rho $=-0.05$ & $0.528^{3}$ \\
\hline HDL & & \\
\hline$<35 \mathrm{mg} / \mathrm{dl}$ & $15.55 \pm 6.18$ & $0.413^{1}$ \\
\hline$>35 \mathrm{mg} / \mathrm{dl}$ & $14.44 \pm 4.74$ & $0.629^{2}$ \\
\hline LDL $(\mathbf{m g} / \mathbf{d l})$ & rho $=-0.13$ & \\
\hline LDL & & \\
\hline$<165 \mathrm{mg} / \mathrm{dl}$ & $15.21 \pm 5.55$ & $0.129^{1}$ \\
\hline$>165 \mathrm{mg} / \mathrm{dl}$ & $14.29 \pm 5.85$ & $0.422^{2}$ \\
\hline VLDL $(\mathbf{m g} / \mathbf{d l})$ & rho $=-0.24$ & \\
\hline VLDL & & \\
\hline$<35 \mathrm{mg} / \mathrm{dl}$ & $18.40 \pm 8.62$ & \\
\hline$>35 \mathrm{mg} / \mathrm{dl}$ & $14.57 \pm 4.95$ & \\
\hline
\end{tabular}

1: Spearman Correlation, 2: Wilcoxon Test, 3: t-test 
Table 3: Association between Duration of Smoking (Years) and Parameters

\begin{tabular}{|l|c|c|}
\hline Parameters & Duration of Smoking (Years) & p value \\
\hline Age (Years) & rho $=0$ & $0.983^{1}$ \\
\hline Total Cholesterol (mg/dl) & rho $=0.55$ & $<0.001^{1}$ \\
\hline Total Cholesterol & & $0.003^{2}$ \\
\hline$<220 \mathrm{mg} / \mathrm{dl}$ & $4.22 \pm 6.54$ & \\
\hline$>220 \mathrm{mg} / \mathrm{dl}$ & $12.00 \pm 8.56$ & $0.001^{1}$ \\
\hline Triglycerides (mg/dl) & rho $=0.5$ & $0.002^{2}$ \\
\hline Triglycerides & & \\
\hline$<160 \mathrm{mg} / \mathrm{dl}$ & $2.81 \pm 6.32$ & \\
\hline$>160 \mathrm{mg} / \mathrm{dl}$ & $10.67 \pm 8.11$ & $0.952^{1}$ \\
\hline HDL $(\mathbf{m g} / \mathbf{d l})$ & rho $=0.01$ & $0.516^{2}$ \\
\hline HDL & & \\
\hline$<35 \mathrm{mg} / \mathrm{dl}$ & $6.86 \pm 8.82$ & $0.008^{1}$ \\
\hline$>35 \mathrm{mg} / \mathrm{dl}$ & $8.33 \pm 7.86$ & $0.748^{2}$ \\
\hline LDL $(\mathbf{m g} / \mathbf{d l})$ & rho $=0.41$ & \\
\hline LDL & & \\
\hline$<165 \mathrm{mg} / \mathrm{dl}$ & $7.30 \pm 8.02$ & $0.878^{1}$ \\
\hline$>165 \mathrm{mg} / \mathrm{dl}$ & $8.57 \pm 10.29$ & $0.879^{2}$ \\
\hline VLDL (mg/dl) & rho $=0.03$ & \\
\hline VLDL & & \\
\hline$<35 \mathrm{mg} / \mathrm{dl}$ & $9.00 \pm 12.45$ & \\
\hline$>35 \mathrm{mg} / \mathrm{dl}$ & $7.31 \pm 7.81$ & \\
\hline$:$ Speaman & & \\
\hline
\end{tabular}

1: Spearman Correlation, 2: Wilcoxon Test

Table 4: Association between Weekly Alcohol Consumption (Grams) and Parameters

\begin{tabular}{|l|c|c|}
\hline Parameters & Weekly Alcohol Consumption (Grams) & p value \\
\hline Age (Years) & rho $=0.47$ & $0.002^{1}$ \\
\hline Total Cholesterol (mg/dl) & rho $=0.5$ & $<0.001^{1}$ \\
\hline Total Cholesterol & & $0.002^{2}$ \\
\hline$<220 \mathrm{mg} / \mathrm{dl}$ & $129.13 \pm 40.33$ & \\
\hline$>220 \mathrm{mg} / \mathrm{dl}$ & $189.12 \pm 56.41$ & $0.005^{1}$ \\
\hline Triglycerides $(\mathbf{m g} / \mathbf{d l})$ & rho $=0.44$ & $0.182^{2}$ \\
\hline Triglycerides & & \\
\hline$<160 \mathrm{mg} / \mathrm{dl}$ & $138.75 \pm 50.97$ & \\
\hline$>160 \mathrm{mg} / \mathrm{dl}$ & $165.21 \pm 57.55$ & $<0.001^{1}$ \\
\hline HDL $(\mathbf{m g} / \mathbf{d l})$ & rho $=-0.65$ & \\
\hline HDL & & $0.001^{2}$ \\
\hline$<35 \mathrm{mg} / \mathrm{dl}$ & $183.86 \pm 49.90$ & \\
\hline$>35 \mathrm{mg} / \mathrm{dl}$ & $118.89 \pm 40.42$ & $0.858^{2}$ \\
\hline LDL $(\mathbf{m g} / \mathbf{d l})$ & rho $=0.06$ & \\
\hline LDL & & $0.412^{1}$ \\
\hline$<165 \mathrm{mg} / \mathrm{dl}$ & $152.88 \pm 53.37$ & $0.376^{2}$ \\
\hline$>165 \mathrm{mg} / \mathrm{dl}$ & $162.86 \pm 70.88$ & \\
\hline VLDL $(\mathbf{m g} / \mathbf{d l})$ & rho $=-0.13$ & \\
\hline VLDL & & $182.00 \pm 82.58$ \\
\hline$<35 \mathrm{mg} / \mathrm{dl}$ & $150.71 \pm 51.54$ & \\
\hline$>35 \mathrm{mg} / \mathrm{dl}$ & &
\end{tabular}

1: Spearman Correlation, 2: Wilcoxon Test 
Table 5: Association between Number of Cigarettes Smoked Per Day and Parameters

\begin{tabular}{|l|c|c|}
\hline Parameters & Number of Cigarettes Smoked Per Day & p value \\
\hline Age (Years) & rho $=-0.04$ & $0.819^{1}$ \\
\hline Total Cholesterol (mg/dl) & rho $=0.57$ & $<0.001^{1}$ \\
\hline Total Cholesterol & & $0.006^{2}$ \\
\hline$<220 \mathrm{mg} / \mathrm{dl}$ & $1.35 \pm 2.19$ & \\
\hline$>220 \mathrm{mg} / \mathrm{dl}$ & $3.41 \pm 2.15$ & $<0.001^{1}$ \\
\hline Triglycerides (mg/dl) & rho $=0.6$ & $<0.001^{2}$ \\
\hline Triglycerides & & \\
\hline$<160 \mathrm{mg} / \mathrm{dl}$ & $0.50 \pm 1.41$ & \\
\hline$>160 \mathrm{mg} / \mathrm{dl}$ & $3.38 \pm 2.20$ & $0.985^{1}$ \\
\hline HDL $(\mathbf{m g} / \mathbf{d l})$ & rho $=0$ & $0.502^{2}$ \\
\hline HDL & & \\
\hline$<35 \mathrm{mg} / \mathrm{dl}$ & $1.95 \pm 2.26$ & $0.051^{1}$ \\
\hline$>35 \mathrm{mg} / \mathrm{dl}$ & $2.56 \pm 2.55$ & $0.528^{2}$ \\
\hline LDL $(\mathbf{m g} / \mathbf{d l})$ & rho $=0.31$ & \\
\hline LDL & & $0.284^{1}$ \\
\hline$<165 \mathrm{mg} / \mathrm{dl}$ & $2.12 \pm 2.36$ & $0.947^{2}$ \\
\hline$>165 \mathrm{mg} / \mathrm{dl}$ & $2.71 \pm 2.63$ & \\
\hline VLDL $(\mathbf{m g} / \mathbf{d l})$ & rho $=0.17$ & \\
\hline VLDL & & \\
\hline$<35 \mathrm{mg} / \mathrm{dl}$ & $2.00 \pm 2.74$ & \\
\hline$>35 \mathrm{mg} / \mathrm{dl}$ & $2.26 \pm 2.37$ & \\
\hline
\end{tabular}

1: Spearman Correlation, 2: Wilcoxon Test

\section{Correlation between Total Cholesterol (mg/dl)} and Weekly Alcohol Consumption (Grams) (n = 40)

The above scatterplot depics the correlation between Total Cholesterol (mg/dl) and Weekly Alcohol Consumption (Grams). Individual points represent individual cases. The blue trendline represents the general trend of correlation between the two variables. The shaded grey area represents the $95 \%$ confidence interval of this trendline.

Non-parametric tests (Spearman Correlation) were used to explore the correlation between the two variables, as at least one of the variables was not normally distributed.

There was a moderate positive correlation between Total Cholesterol (mg/dl) and Weekly Alcohol Consumption (Grams), and this correlation was statistically significant (rho = $0.50, \mathrm{p}=<0.001)$.

For every 1 unit increase in Total Cholesterol $(\mathrm{mg} / \mathrm{dl})$, the Weekly Alcohol Consumption (Grams) increases by 0.58 units.
The bar graph below depicts the means of Weekly Alcohol Consumption (Grams) in the 2 different groups.

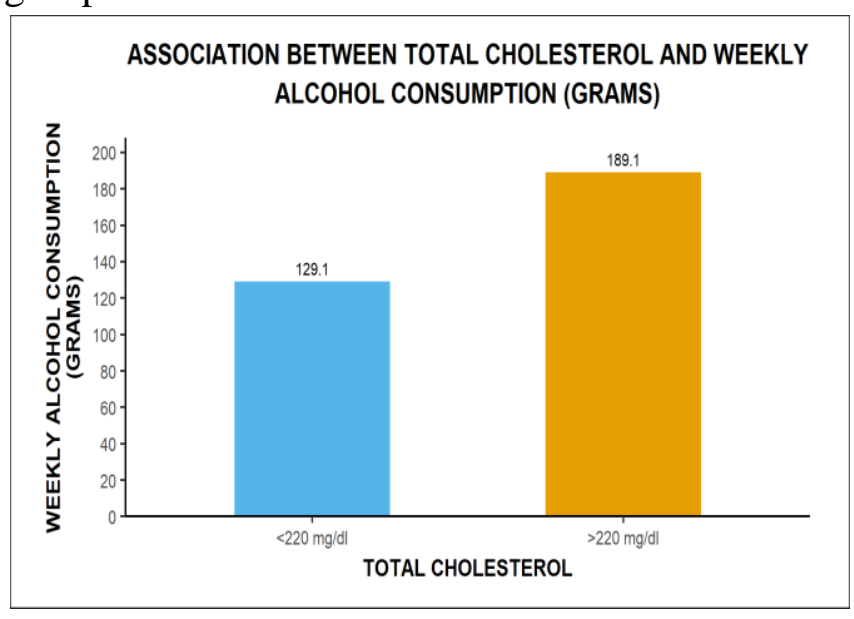

Correlation between Triglycerides (mg/dl) and Weekly Alcohol Consumption (Grams) $(\mathbf{n}=\mathbf{4 0})$ The above scatterplot depics the correlation between Triglycerides (mg/dl) and Weekly Alcohol Consumption (Grams). Individual points represent individual cases. The blue trendline represents the general trend of correlation between the two variables. The shaded grey area represents the $95 \%$ confidence interval of this trendline. 
Non-parametric tests (Spearman Correlation) were used to explore the correlation between the two variables, as at least one of the variables was not normally distributed.

There was a moderate positive correlation between Triglycerides (mg/dl) and Weekly Alcohol Consumption (Grams), and this correlation was statistically significant (rho = 0.44, $\mathrm{p}=0.005$ ).

For every 1 unit increase in Triglycerides $(\mathrm{mg} / \mathrm{dl})$, the Weekly Alcohol Consumption (Grams) increases by 0.54 units.For every 1 unit increase in Triglycerides (mg/dl), the Weekly Alcohol Consumption (Grams) increases by 0.54 units.

The bar graph below depicts the means of Weekly Alcohol Consumption (Grams) in the 2 different groups.

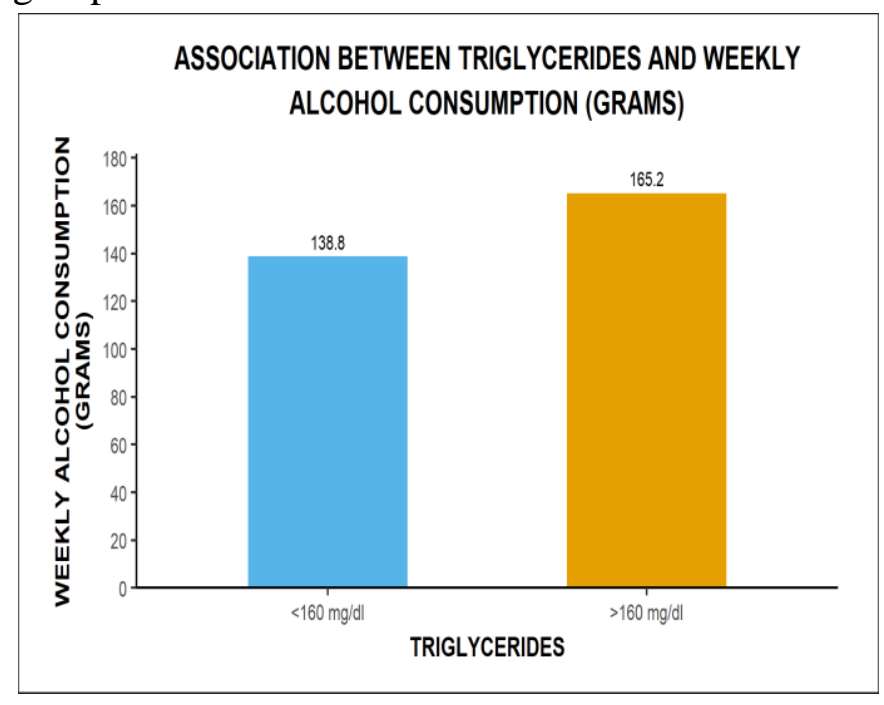

Correlation between HDL (mg/dl) and Weekly Alcohol Consumption (Grams) $(n=40)$

The above scatterplot depics the correlation between HDL (mg/dl) and Weekly Alcohol Consumption (Grams). Individual points represent individual cases. The blue trendline represents the general trend of correlation between the two variables. The shaded grey area represents the 95\% confidence interval of this trendline.

Non-parametric tests (Spearman Correlation) were used to explore the correlation between the two variables, as at least one of the variables was not normally distributed.

There was a strong negative correlation between HDL (mg/dl) and Weekly Alcohol Consumption
(Grams), and this correlation was statistically significant ( $r h o=-0.65, p=<0.001$ ).

For every 1 unit increase in HDL $(\mathrm{mg} / \mathrm{dl})$, the Weekly Alcohol Consumption (Grams) decreases by 5.25 units.

The bar graph below depicts the means of Weekly Alcohol Consumption (Grams) in the 2 different groups.

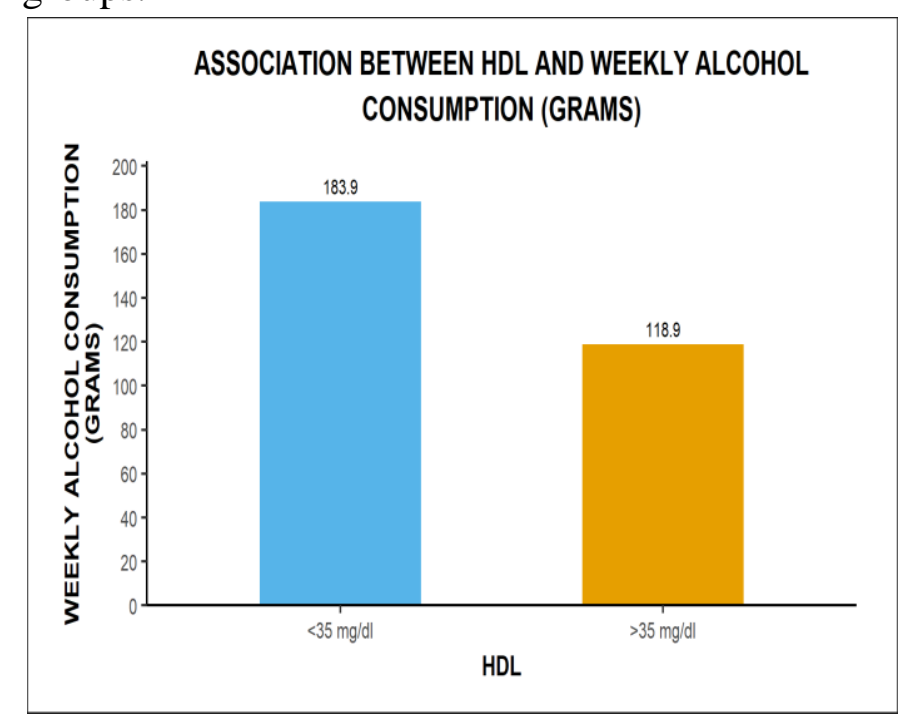

Correlation between LDL (mg/dl) and Weekly Alcohol Consumption (Grams) $(\mathbf{n}=\mathbf{4 0})$

The above scatterplot depics the correlation between LDL (mg/dl) and Weekly Alcohol Consumption (Grams). Individual points represent individual cases. The blue trendline represents the general trend of correlation between the two variables. The shaded grey area represents the 95\% confidence interval of this trendline.

Non-parametric tests (Spearman Correlation) were used to explore the correlation between the two variables, as at least one of the variables was not normally distributed.

There was a weak positive correlation between LDL (mg/dl) and Weekly Alcohol Consumption (Grams), and this correlation was not statistically significant ( $\mathrm{rho}=0.06, \mathrm{p}=0.724$ ).

The bar graph below depicts the means of Weekly Alcohol Consumption (Grams) in the 2 different groups. 


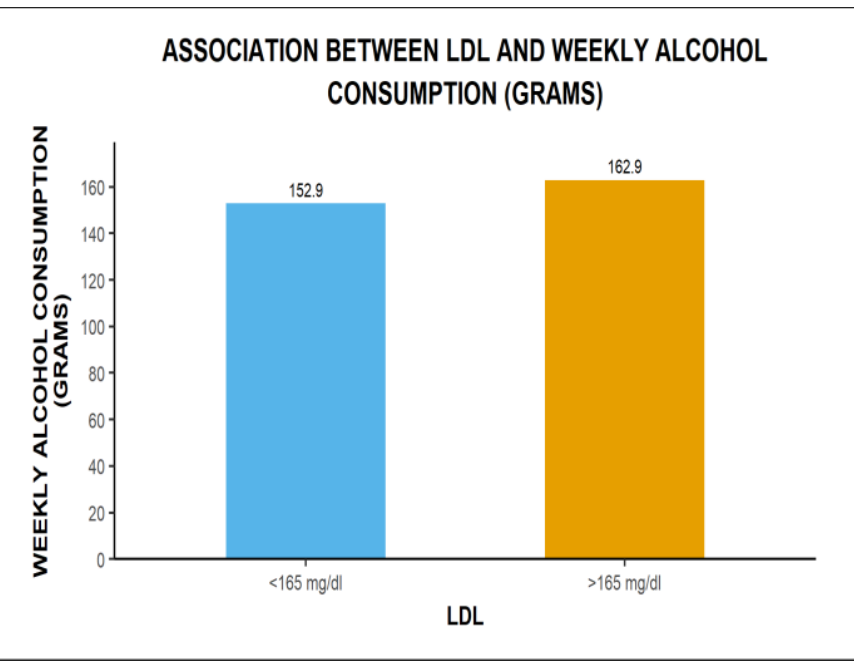

Correlation between VLDL (mg/dl) and Weekly Alcohol Consumption (Grams) $(\mathbf{n}=40)$

The above scatterplot depics the correlation between VLDL (mg/dl) and Weekly Alcohol Consumption (Grams). Individual points represent individual cases. The blue trendline represents the general trend of correlation between the two variables. The shaded grey area represents the 95\% confidence interval of this trendline.

Non-parametric tests (Spearman Correlation) were used to explore the correlation between the two variables, as at least one of the variables was not normally distributed.

There was a weak negative correlation between VLDL (mg/dl) and Weekly Alcohol Consumption (Grams), and this correlation was not statistically significant (rho $=-0.13, \mathrm{p}=0.412$ ).

The bar graph below depicts the means of Weekly Alcohol Consumption (Grams) in the 2 different groups.

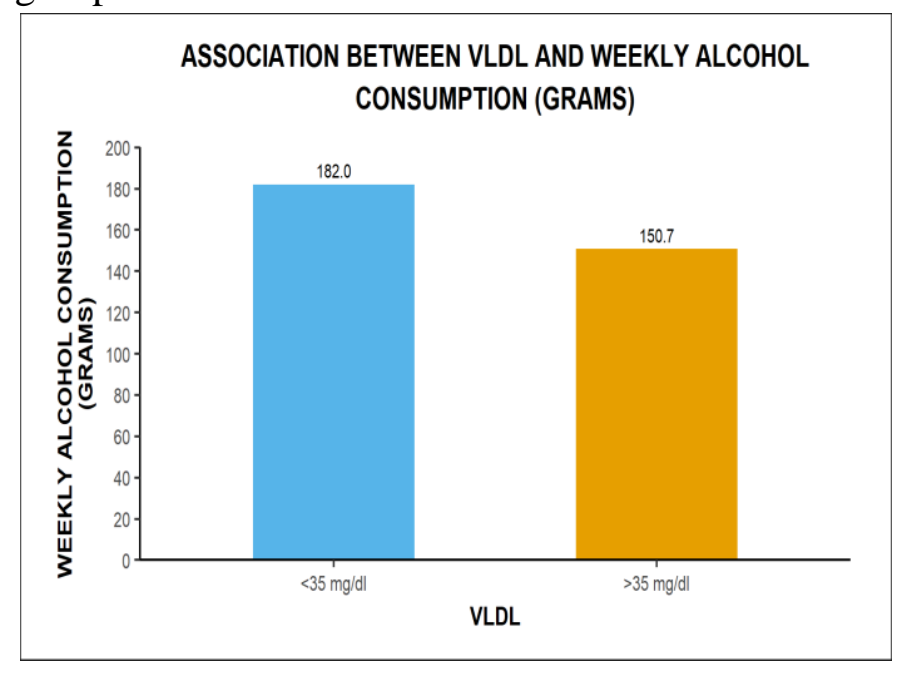

\section{Discussion}

Alcohol is a psychoactive substance with dependence-producing properties. As described in this report, consumption of alcohol and problems related to alcohol vary widely around the world, but the burden of disease and death remains significant in most countries. The harmful use of alcohol ranks among the top five risk factors for disease, disability and death throughout the world [WHO; 2011a, Lim SS et al;2012]. Alcoholrelated harm is determined by the volume of alcohol consumed, the pattern of drinking, and, on rare occasions, the quality of alcohol consumed. A wide range of global, regional and national policies and actions are in place to reduce the harmful use of alcohol. Worldwide about $16.0 \%$ of drinkers aged 15 years or older engage in heavy episodic drinking. In 2012139 million DALYs (disability adjusted life years), or $5.1 \%$ of the global burden of disease and injury, were attributable to alcohol consumption. Factors affecting alcohol consumption and alcohol related harm are age (more intake of alcohol among adolescent and middle age group), gender (males are more prone to alcohol dependence than females), familial risk factors(parental use of alcohol negatively affects the childhood) and socioeconomic status (high in higher socioeconomic group).

In this study, the mean (SD) of Age (Years) were 53.77 (5.63). The Age (Years) ranged from 42 64. The mean (SD) of Duration of Alcohol Use (Years) were 15.05 (5.54). The Duration of Alcohol Use (Years) ranged from 7 - 30. The mean (SD) of Duration of Smoking (Years) was 7.53 (8.33). The Duration of Smoking (Years) ranged from 0 - 25. The mean (SD) of Weekly Alcohol Consumption (Grams) were 154.62 (55.90). The Weekly Alcohol Consumption (Grams) ranged from 80 - 280. The variable Number of Cigarettes Smoked Per Day was not normally distributed (Shapiro-Wilk Test: $\mathrm{p}=$ $<0.001)$.

The mean (SD) of Number of Cigarettes Smoked Per Day were 2.23 (2.38). The Number of 
Cigarettes Smoked Per Day ranged from 0 - 7. The mean (SD) of Total Cholesterol $(\mathrm{mg} / \mathrm{dl})$ were 197.47 (51.65). The Total Cholesterol (mg/dl) ranged from 96 - 338. The mean (SD) of Triglycerides (mg/dl) were 182.00 (45.10). The Triglycerides $(\mathrm{mg} / \mathrm{dl})$ ranged from $105-260$. The mean (SD) of HDL (mg/dl) were 33.80 (6.89). The HDL (mg/dl) ranged from 24 - 46. The mean (SD) of LDL (mg/dl) were 144.00 (26.01). The LDL (mg/dl) ranged from 80 - 195. The mean (SD) of VLDL (mg/dl) were 50.15 (12.27). The VLDL (mg/dl) ranged from 20 - 69 .

The mean (SD) of Duration of Alcohol Use (Years) in the Total Cholesterol: $<220 \mathrm{mg} / \mathrm{dl}$ group were 14.52 (5.88). The mean (SD) of Duration of Alcohol Use (Years) in the Total Cholesterol: >220 mg/dl group were 15.76 (5.12). The mean (SD) of Duration of Alcohol Use (Years) in the Triglycerides: $<160 \mathrm{mg} / \mathrm{dl}$ group were 14.00 (5.65). The mean (SD) of Duration of Alcohol Use (Years) in the Triglycerides: >160 $\mathrm{mg} / \mathrm{dl}$ group were 15.75 (5.47). The mean (SD) of Duration of Alcohol Use (Years) in the HDL: <35 $\mathrm{mg} / \mathrm{dl}$ group were 15.55 (6.1 The mean (SD) of Duration of Alcohol Use (Years) in the LDL: $<165 \mathrm{mg} / \mathrm{dl}$ group were 15.21 (5.55). The mean (SD) of Duration of Alcohol Use (Years) in the LDL: >165 mg/dl group was 14.29 (5.85). 8). The mean (SD) of Duration of Alcohol Use (Years) in the HDL: >35 mg/dl group were 14.44 (4.74). The mean (SD) of Duration of Alcohol Use (Years) in the VLDL: <35 mg/dl group was 18.40 (8.62). The mean (SD) of Duration of Alcohol Use (Years) in the VLDL: >35 mg/dl group were 14.57 (4.95). The mean (SD) of Duration of Smoking (Years) in the Total Cholesterol: <220 $\mathrm{mg} / \mathrm{dl}$ group were 4.22 (6.54). The mean (SD) of Duration of Smoking (Years) in the Total Cholesterol: >220 mg/dl group were 12.00 (8.56). Triglycerides.

The mean (SD) of Duration of Smoking (Years) in the Triglycerides: $<160 \mathrm{mg} / \mathrm{dl}$ group were 2.81 (6.32). The mean (SD) of Duration of Smoking (Years) in the Triglycerides: $>160 \mathrm{mg} / \mathrm{dl}$ group were 10.67 (8.11). The mean (SD) of Duration of
Smoking (Years) in the HDL: <35 mg/dl group were 6.86 (8.82). The mean (SD) of Duration of Smoking (Years) in the HDL: >35 mg/dl group were 8.33 (7.86). The mean (SD) of Duration of Smoking (Years) in the LDL: $<165 \mathrm{mg} / \mathrm{dl}$ group were 7.30 (8.02). The mean (SD) of Duration of Smoking (Years) in the LDL: $>165 \mathrm{mg} / \mathrm{dl}$ group were 8.57 (10.29. The mean (SD) of Duration of Smoking (Years) in the VLDL: $<35 \mathrm{mg} / \mathrm{dl}$ group were 9.00 (12.45). The mean (SD) of Duration of Smoking (Years) in the VLDL: > $35 \mathrm{mg} / \mathrm{dl}$ group were 7.31 (7.81).

The mean (SD) of Number of Cigarettes Smoked Per Day in the Total Cholesterol: $<220 \mathrm{mg} / \mathrm{dl}$ group were 1.35 (2.19). The mean (SD) of Number of Cigarettes Smoked Per Day in the Total Cholesterol: >220 mg/dl group were 3.41 (2.15). The mean (SD) of Number of Cigarettes Smoked Per Day in the Triglycerides: $<160 \mathrm{mg} / \mathrm{dl}$ group were 0.50 (1.41). The mean (SD) of Number of Cigarettes Smoked Per Day in the Triglycerides: > $160 \mathrm{mg} / \mathrm{dl}$ group were 3.38 (2.20). The mean (SD) of Number of Cigarettes Smoked Per Day in the HDL: $<35 \mathrm{mg} / \mathrm{dl}$ group were 1.95 (2.26). The mean (SD) of Number of Cigarettes Smoked Per Day in the HDL: >35 mg/dl group were 2.56 (2.55). The mean (SD) of Number of Cigarettes Smoked Per Day in the LDL: <165 $\mathrm{mg} / \mathrm{dl}$ group were 2.12 (2.36). The mean (SD) of Number of Cigarettes Smoked Per Day in the LDL: >165 mg/dl group were 2.71 (2.63). The mean (SD) of Number of Cigarettes Smoked Per Day in the VLDL: $<35 \mathrm{mg} / \mathrm{dl}$ group were 2.00 (2.74). The mean (SD) of Number of Cigarettes Smoked Per Day in the VLDL: > $35 \mathrm{mg} / \mathrm{dl}$ group were 2.26 (2.37).

For every 1 unit increase in Total Cholesterol $(\mathrm{mg} / \mathrm{dl})$, the Weekly Alcohol Consumption (Grams) increases by 0.58 units. For every 1 unit increase in HDL $(\mathrm{mg} / \mathrm{dl})$, the Weekly Alcohol Consumption (Grams) decreases by 5.25 units. There was a weak positive correlation between LDL (mg/dl) and Weekly Alcohol Consumption (Grams), and this correlation was not statistically significant (rho $=0.06, \mathrm{p}=0.724$ ). There was a 
weak negative correlation between VLDL (mg/dl) and Weekly Alcohol Consumption (Grams), and this correlation was not statistically significant (rho $=-0.13, \mathrm{p}=0.412$ ).

Alcohol consumption can have both health and social consequences for the drinkers as it poses harmful effects in the family, friends, co-workers and at work-place and socio-economic burden at a large. WHO has formulated a global strategy to reduce harmful use of alcohol [WHO;2010a]. Effects of chronic intake of alcohol are profound on major systems of the body. Cardiac problems are increased with heavy intake of alcohol. So, to decrease the burden of heart diseases, steps should be taken for decreasing the intake of alcohol at a large.

\section{Limitations}

Less statistical power due to small study population and single center study, small duration were the limitations of this study.

\section{Conclusion}

In conclusion, this study underscores the need for the implementation of smoking and alcohol prevention and health promotion programmes focusing on young adolescents in primary and secondary school to reduce the cardiovascular mortality in the population due to hyperlipidemia.

\section{References}

1. Kanwar G, Shekhawat M, Sharma N, Mehra MC. Comparative Study of Serum Lipid Profile in Alcoholics and NonAlcoholics.Internation Journal of advanced Research in Science,Engineering and Technology 2016;3(2):1414-9.

2. Mammas IN, Bertsias GK, Linardakis M, Tzanakis NE, Labadarios DN, Kafatos AG. Cigarette smoking, alcohol consumption, and serum lipid profile among medical students in Greece. The European Journal of Public Health 2003;13(3):278-82.
3. Park H, Kim K. Association of alcohol consumption with lipid profile in hypertensive men. Alcohol and Alcoholism 2012;47(3):282-7.

4. Boemeke L, Bassani L, Marroni CA, Gottschall CB. Lipid profile in cirrhotic patients and its relation to clinical outcome..ArquivosBrasileiros de CirurgiaDigestiva (São Paulo) 2015;28(2):132-5.

5. Labadarios D, Kafatos A. Teaching of clinical nutrition at the University of Crete, School of Medicine, Greece. Nutrition 1991;7(1):61-3.

6. Fossati P, Prencipe L. Serum triglycerides determined colorimetrically with an enzyme that produces hydrogen peroxide. ClinChem 1982;28:2077-80.

7. Allain CC, Poon LS, Chan CSG, Richmond W, Fu PC. Enzymatic determination of total serum cholesterol. ClinChem 1974;20:470-5.

8. Finley PR, Schifman RB, Williams RJ, Lichti DA. Cholesterol in high-density lipoprotein: use of $\mathrm{Mg} 2+/$ dextran sulfate in its enzymatic measurement. ClinChem 1978;24:931. 